\title{
The Economic Contribution of Industry-Sponsored Pharmaceutical Clinical Trials
}

Dat T. Tran ${ }^{1,2}$; Ilke Akpinarr ${ }^{2}$; Richard N. Fedorak ${ }^{3}$; Egon Jonsson²; John R. Mackey ${ }^{4}$; Lawrence Richer ${ }^{5}$; Philip Jacobs ${ }^{2,3}$

(1) School of Public Health, University of Alberta; (2) Institute of Health Economics; (3) Department of Medicine, University of Alberta; (4) Department of Oncology, University of Alberta; (5) Department of Pediatrics, University of Alberta, Edmonton, Alberta, Canada

Received, September 22, 2017; Revised, November 15, 2017; Accepted, November 16, 2017; Published, November 20 , 2017

\begin{abstract}
Purpose. In pharmaceutical clinical trials, industrial sponsors pay for study drugs and related healthcare services. We conducted a study to determine industry's economic contribution of these trials to the Alberta healthcare system. Methods: We used data from two trial centers for cancer and non-cancer trials at the University of Alberta. For each trial (cancer, non-cancer), we calculated the cost of drugs provided by the sponsors using the market price, the cost of clinical services, and the cost of administrative services that they paid. We extrapolated these results to all trials in Alberta based on information obtained from the registration website ClinicalTrials.gov. Results: Our sample consisted of 40 non-cancer and 39 cancer drug trials which were initiated in 2012. The monetary value of the industry sponsors' contribution was $\$ 799,055$ per non-cancer and \$630,243 per cancer drug trial. Drugs (in-trial and post-trial) accounted for $84 \%$ of the total contribution of the non-cancer drug trials whereas it represented $93 \%$ of all trial-related contributions in the cancer category. The total province-wide contribution of industry-sponsored drug trials which were initiated in 2012 was estimated to be \$101 million, including open-label drugs in the non-cancer category. Conclusions: Industrysponsored pharmaceutical trials represent a major economic contributor to clinical research within the province.
\end{abstract}

This article is open to POST-PUBLICATION REVIEW. Registered readers (see "For Readers") may comment by clicking on ABSTRACT on the issue's contents page.

\section{INTRODUCTION}

The data collected in clinical trials (CTs) form the basis for many types of assessments, including safety, efficacy, effectiveness and costeffectiveness, which all provide essential information in reimbursement decisions as well as in other health policy making. CTs also play a role in the payment of health services since the sponsoring industry has to provide new drugs and services such as diagnostic testing, therapeutic applications, and follow up examinations free of charge to the patients in a trial. This healthcare otherwise would have to be funded through other sources of funding such as the government, private insurance, and consumers. CTs are also research activities, which are important precursors to innovation; thus they are also important from an industrial policy viewpoint.

Earlier research on CT costs focused on pharmaceutical costs avoided by specific payers by pharmacies, hospitals, clinics or academic centers - due to CTs (1-6). A majority of published studies demonstrated significant savings to specific payers resulting from the provision (by industry) of drugs. However, these are all partial analyses, focusing on a single payer or entity. To our knowledge there is no study available to demonstrate the full economic contribution of commercial pharmaceutical CTs for a province or an entire country, incorporating both funded clinical services as well as drugs.

The purpose of this paper is to report on an assessment of the total economic contribution to the healthcare system of Alberta from industrysponsored phase II and III pharmaceutical CTs. This includes calculations of the contribution as expressed in the relevant market prices of the drugs, all clinical services such as testing, laboratory and

Correspondence Author: Philip Jacobs, Institute of Health Economics, \#1200 - 10405 Jasper Avenue, Edmonton, Alberta T5J 3N4. Tel. 780-448-4881, Fax. 780-448-0018, Email: pjacobs@ihe.ca 
imaging services, and administrative activities. This allows us to assess the impact of these CTs in terms of their provision for care, the avoidance of costs by payers, and their contribution to clinical research.

\section{METHODS}

\section{Environment}

The healthcare system in Alberta has a single province-wide institutional service provider Alberta Health Services (AHS). Pharmaceuticals are funded by a variety of public and private programs. Cancer drugs are funded by the public cancer agency, Alberta Health Services Cancer Control (AHSCC) which is part of AHS. In Canada, public programs provided $42 \%$ of out-of-hospital drug funding, third party non-government insurers provided $35.8 \%$ and households directly paid $22.2 \%$ (7). The replacement cost for drugs will impact both public and private funders.

Sample data on trials were obtained from two sources, one for non-cancer drug trials and the other for cancer drug trials. The data source for noncancer related CTs was the Northern Alberta Clinical Trials and Research Center (NACTRC) - a joint venture of the University of Alberta and AHS. NACTRC is responsible for negotiating clinical trial agreements and approvals to conduct research within AHS clinics and hospitals. The data source for cancer CTs was AHSCC which administers negotiations and approvals in a similar way to NACTRC. Data describing the CT including protocols and budgets are maintained in central databases - one for each of the centers. Budgeted prices for clinical services and overheads which go into the contracts are set by AHS-Finance and reflect actual costs. Research teams submit the invoices which cover costs for AHS and investigator services to the trial sponsors (industry). Payments are received and deposited in AHS accounts. Investigators and their teams manage expenses and payment tracking and make reimbursement (e.g., salary) submissions to AHSFinance for team activities (research staff are employees of AHS).

\section{Variables of Interest}

The variables included in our analysis which describe the industry contribution are (1) the market value of pharmaceuticals provided in the trials, (2) revenues billed to and received from industry for clinical and other services, and (3) administrative expenses related to each trial. These items were calculated based on the market value of drugs and, for non-drug services, the revenues from services that were billed to industry for each enrollee, as per the trial budgets. The data collected for our study were drawn from trials that were started during 2012 and lasted up to four years later - September 2016, which is the ending date we chose for our analysis. We chose this start date to allow for sufficient time for the trials to end. For those trials with a 2012 start and which were ended by September 2016, all of the costs covered were included in our estimates. The estimated average value per CT formed the basis to estimate the value of all CTs in the province. For the number of CTs in the entire province, we used the total number of industry-sponsored CTs which were newly enrolled in 2012 as per the website ClinicalTrials.gov (8).

\section{Trial Sample}

Our target sample included all industry-sponsored pharmaceutical CTs that were processed through NACTRC (non-cancer CTs) and AHSCC (cancer CTs), and were initiated during 2012. We obtained the budgets from NACTRC and AHSCC. We obtained the number of patients enrolled in each trial from the University of Alberta Research Ethics Board. We contacted principal investigators of ongoing (that is, non-completed) trials to obtain budgets and the number of patients enrolled by the study end date of September 30th, 2016.

\section{Estimating Industry Billings for Clinical Services - Trial Component}

We used trial budgets to measure billings for each trial. In the absence of a trial, these billings would have been paid for by the healthcare system as part of standard of care. We measured service costs according to trial protocols and categorized billed services into three major groups: 1) management billings (including start-up costs, pharmacy maintenance costs, document preparation and archival costs, and costs of advertisement, adverse event and investigational new drug safety reporting), 2) ethics review fee, and 3) patient service billings (screening, procedures, consultations, treatments of adverse events, laboratory tests and imaging procedures). Billings of individual trials were summed to yield total billings of the study sample. Budget rates included 
direct service costs plus estimated overheads.

\section{Estimating the Contribution of Industry- Provided Drugs - Trial Component}

We used the CT protocols from the website ClinicalTrials.gov to identify drugs used in the study, their average dosages and treatment lengths in study trials. We then developed a hierarchical method to identify the unit price of each drug used in study trials (9). Firstly, we used the Alberta Health Drug Benefit List (ADBL) (10) to provide a market dollar value for a unit of the drug in the trial (32 drugs). The ADBL price is that funded by the government. If a price was not found in the ADBL, we used the United States Federal Supply Schedule (FSS) price of the same dosage and packaging provided by the Department of Veteran Affairs Drug List (VADL; 46 drugs) (11) and converted it to Canadian prices using the Bank of Canada exchange rate (1 US\$ equaled 1.29 CA\$) (12). If a price was not found in either the ADBL or VADL, we used Medscape.com (13) to identify an alternative drug that was equivalent in indication and used the alternative drug for pricing (13 alternative drugs using ADBL price and 3 alternative drugs using VADL price). If an alternative drug could not be identified, we used the price of the drug used for the control patients in the trial (2 control drugs using ADBL price). We also searched for drug prices in cost-effectiveness studies in the literature and used the daily drug cost provided; this occurred in one study (14). Finally, if none of the above methods was available, we used the listed price of active compounds from Selleckchem (15) and Medchem Express (16) for drugs that were not registered in any other jurisdiction (14 drugs). The cost of placebo drugs was set to nil. The source of pricing for CT drugs is presented in Table 1.

Ribavirin was used in 9 out of 40 (22.5\%) non-cancer drug trials. There were two prices of Ribavirin listed in the ADBL: MODERIBA brand priced $\$ 0.01$ per $600 \mathrm{mg}$ tablet and IBAVYR priced $\$ 21.75$ per $600 \mathrm{mg}$ tablet (10). The lower price was only available for patients who were also prescribed another specific drug (Holkira Pak) for Hepatitis C from the same sponsoring company (17). Therefore, we used the MODERIBA price in 2 trials that met this condition. The IBAVYR price was used in the other 7 trials.

\section{Estimating the Cost of Industry Provided Drugs - Post-Trial Component}

Some trial sponsors had agreed to continue providing drugs free-of-charge to patients even after closing the trial. We used reports from the ethics committee of the University of Alberta to identify whether there was post-trial drug provision and obtained open label closing dates from investigators. We assumed that patients would continue to be on the same drugs with the same dosing as during the period of the trials.

\section{Estimating Province-Wide Contribution of} Industry-Sponsored Clinical Trials

We multiplied the estimated average value per trial with the number of industry-sponsored non-cancer and cancer drug CTs (separately) that were initiated during 2012 to estimate the total value of all industry-sponsored drug CTs in the province.

Table 1: Source of CT drug pricing

\begin{tabular}{lccc}
\hline Pricing category & $\begin{array}{c}\text { Non-cancer drug } \\
\text { CT }\end{array}$ & $\begin{array}{c}\text { Cancer drug } \\
\text { CT }\end{array}$ & All \\
\hline All drugs, $\mathrm{N}$ & 54 & 57 & 111 \\
\hline Alberta Drug Benefit List (ADBL), $\mathrm{n}$ & 22 & 10 & 32 \\
\hline Department of Veteran Affairs Drug List (VADL), $\mathrm{n}$ & 9 & 37 & 46 \\
\hline Alternative drug pricing & & 0 & 13 \\
\hline \multicolumn{1}{l}{ Using ADBL price, $n$} & 13 & 2 & 3 \\
\hline \multicolumn{1}{l}{ Using VADL price, $n$} & 1 & 0 & 2 \\
\hline Using control drug price (ADBL), $\mathrm{n}$ & 2 & 0 & 1 \\
\hline Using price in economic evaluation, $\mathrm{n}$ & 1 & 8 & 14 \\
\hline $\begin{array}{l}\text { Using listed price at Selleckchem and Medchem } \\
\text { Express, } \mathrm{n}\end{array}$ & 6 & & \\
\end{tabular}




\section{Sensitivity Analyses of Drug Prices}

We used the price on the Alberta Drug Benefit List as our first choice. This covered 37/54 (69\%) of non-cancer drugs and 10/57 (18\%) of cancer drugs. The list with the second highest number of drugs was the VA FSS schedule; we used this schedule for 10/54 (19\%) of non-cancer and 39/57 (68\%) of cancer drugs. Patented Medicine Price Review Board (PMPRB) reported that drug prices in the United States could be approximately 2.7 times higher than in Canada (18). Therefore, we used the original US price in the base case analysis and conducted a sensitivity analysis in which the US price was lowered to a maximum of 2.7 times to examine its effects on the total drug costs in both non-cancer and cancer drug CTs.

\section{Statistical Analyses}

Total economic values and values per enrollee were calculated for drug by arm (experimental and control arms and post-trial phase) and for management and procedures by major categories (management billings, ethic review fee, and patient service billings) and were reported in determined values. There was a large heterogeneity between trials regarding type of diseases, clinical procedures, laboratory tests, and type of drug used. Therefore, we did not report variation for economic values as it would be less informative. All monetary values were presented in current Canadian dollars. We did not include inflation adjustments because of the short time frames and low inflation rates during the period. We also calculated length of each CT in month from its start date to its end date or to our study end date of September $30^{\text {th }}$, 2016, which ever came first, and reported CT length in mean ( \pm standard deviation). All analyses were performed using Microsoft Excel version 2013 (Microsoft Corp., Redmond, Washington) and Stata version 14 (Stata Corp., College Station, Texas).

\section{RESULTS}

In total, there were 41 non-cancer drug trials and 43 cancer drug trials initiated in 2012 that were industry sponsored. One non-cancer drug trial was excluded due to the unavailability of drug data and four cancer drug trials were excluded because of missing budgets. We obtained complete data on 40 non-cancer trials and 39 cancer trials. The number of participants in the experimental and control groups are shown in Table 2.

The mean duration for the experimental phases of the non-cancer trials was 25.2 months ( \pm 14.2 months, min 5.1 months, max 54.8 months) up to the end of our study in September, 2016. For the post-experimental, open label components of 5 continuing trials, there were 40 patients. In two of these trials (28 patients) provision of the drugs was continuing free of charge even after the cut-off date of the trial. For cancer trials, the mean duration for the experimental phases was 38.7 months $( \pm 13.6$ months, min. 8 months, max. 55.2 months). No data on post-trial phases were available for cancer trials.

Economic Value of Clinical Services Provided in Standard Care as Part of the Clinical Trials

Non-cancer standard of care patient service billings accounted for $\$ 4.4$ million whereas $\$ 0.9$ million were related to management fees and review boards. The equivalent for standard of care for cancer patient services billings was $\$ 1.3$ million and $\$ 0.36$ million (Table 2).

\section{Economic Cost of Drugs Provided as Part of the Clinical Trials}

The total drug contribution for non-cancer drugs was $\$ 13.5$ million excluding post-trial drugs and \$26.7 million including post-trial drugs (Table 2). Drugs accounted for $72 \%$ (excluding open-label drugs) and $84 \%$ (including open-label drugs) of the total contribution of the non-cancer drug trials. The total contribution for cancer drugs, inclusive of the experimental and control groups was \$22.9 million, which represented $93 \%$ of all CT sponsor contributions in the cancer category (Table 2). It should be noted, however, that data on post-trial drugs were not available for cancer trials.

\section{Summary of Industry Contribution}

In summary the total values for the non-cancer and cancer drug CTs examined were \$32 million and $\$ 24.6$ million, respectively (Table 2). On a perpatient enrolled basis the contributions to the health care system were $\$ 127,339$ (with post-trial drugs) and $\$ 74,471$ (without post-trial drugs) for noncancer drug CTs, and \$225,500 for cancer drug CTs (without post-trial drugs). These values can be viewed as replacement costs for publicly funded healthcare including clinical and pharmaceutical services that have been provided in the trial. On a per-trial basis, the industrial contribution to the 
Table 2: Summary economic data for sample

\begin{tabular}{|c|c|c|c|c|}
\hline Variable & $\begin{array}{l}\text { Number } \\
\text { of trials }\end{array}$ & $\begin{array}{l}\begin{array}{l}\text { Number } \\
\text { enrollees }\end{array} \\
\end{array}$ & Total value (\$) & $\begin{array}{l}\text { Value per } \\
\text { enrollee, \$, mean }\end{array}$ \\
\hline Non-cancer drug trials & 40 & & & \\
\hline \multicolumn{5}{|l|}{ Pharmaceuticals } \\
\hline Experimental arm & & 188 & $12,967,076$ & 68,974 \\
\hline Control arm & & 63 & 499,758 & 7,933 \\
\hline Post-trial (open label) & & 40 & $13,270,060$ & 331,752 \\
\hline \multicolumn{5}{|c|}{ Trial management, procedures } \\
\hline Management billings & & & 748,852 & 2,983 \\
\hline Ethic review fees & & & 121,601 & 484 \\
\hline Patient service billings & & & $4,354,849$ & 17,350 \\
\hline \multicolumn{5}{|l|}{ Overall for all enrollees } \\
\hline Excluding post-trial & & 251 & $18,692,135$ & 74,471 \\
\hline Including post-trial & & 251 & $31,962,195$ & 127,339 \\
\hline Cancer drug trials & 39 & & & \\
\hline \multicolumn{5}{|l|}{ Pharmaceuticals } \\
\hline Experimental arm & & 102 & $22,592,225$ & 221,492 \\
\hline Control arm & & 7 & 326,576 & 46,654 \\
\hline Post-trial (open label) & & N/A & & \\
\hline \multicolumn{5}{|c|}{ Trial management, procedures } \\
\hline Management billings & & & 280,003 & 2,569 \\
\hline Ethic review fees & & & 82,595 & 758 \\
\hline Patient service billings & & & $1,298,069$ & 11,909 \\
\hline \multicolumn{5}{|l|}{ Overall for all enrollees } \\
\hline Excluding post-trial & & 109 & $24,579,468$ & 225,500 \\
\hline
\end{tabular}

healthcare system is $\$ 799,055$ and $\$ 630,243$ per non-cancer and cancer drug CTs, respectively (Table 3).

\section{Province-Wide Costs of Clinical Trials - An Extrapolation}

We extrapolated these contributions to the entire province of Alberta for CTs initiated in 2012 (Table 3). Excluding post-trial components, the value to the healthcare system of industrysponsored drug CTs in the province of Alberta in 2012 was $\$ 72.2$ million. This value approximates the annual value of CTs initiated each year in the province of Alberta as industry-sponsored CT numbers have remained relatively constant over the last decade. If post-trial components were included this value reached \$101 million.

\section{Sensitivity Analyses}

Using a maximum US/Canada drug price ratio of 2.7 led to a reduction of $\$ 2.4, \$ 0.2$, and $\$ 0.5$ million in experimental arm, control arm, and post-trial drug costs, respectively, in non-cancer drug CTs. This resulted in a reduction of the revenue per trial for non-cancer drug CTs from $\$ 799,055$ to $\$ 720,923$ (with post-trial drugs) and from $\$ 467,303$ to $\$ 401.990$ (without post-trial drugs). Similarly, lowering US drug prices led to a reduction of \$12.5 and $\$ 0.2$ million in experimental and control arm drug costs, respectively, in cancer drug CTs. Accordingly, the revenue per trial for cancer drug CTs reduced from $\$ 630,243$ per trial to $\$ 305,255$ 
Table 3: Extrapolation of sample results to province of Alberta

\begin{tabular}{lcccccc}
\hline & \multicolumn{9}{c}{ Excluding post-trial components } & \multicolumn{2}{c}{ Including post-trial components } \\
\hline & $\begin{array}{l}\text { Number of } \\
\text { registered } \\
\text { trials* }\end{array}$ & $\begin{array}{l}\text { Revenue } \quad \begin{array}{c}\text { per } \\
\text { trial, \$, mean** }\end{array} \\
\text { Group }\end{array}$ & $\begin{array}{l}\text { Total } \\
\text { generated, \$ }\end{array}$ & $\begin{array}{l}\text { revenue } \\
\text { Revenue } \\
\text { trial, \$, mean** }\end{array}$ per & $\begin{array}{l}\text { Total } \\
\text { generated, \$ }\end{array}$ \\
\hline Non-cancer drugs & 87 & 467,303 & $40,655,394$ & & 799,055 & $69,517,755$ \\
\hline Cancer drugs & 50 & 630,243 & $31,512,138$ & 630,243 & $31,512,138$ \\
\hline Both groups & & & $\mathbf{7 2 , 1 6 7 , 5 3 3}$ & & $\mathbf{1 0 1 , 0 2 9 , 9 1 4}$ \\
\hline
\end{tabular}

* Registered trials in 2012 as per ClinicalTrials.gov

** Based on values in Table 2

per trial. Finally, the province-wide contribution of industry-sponsored drug CTs fell from \$102 million to $\$ 78$ million (with post-trial drugs) and from $\$ 72.2$ million to $\$ 50.2$ million (without post-trial drugs).

\section{DISCUSSION}

We estimated the economic contribution by industry of industry-sponsored phase II and III drug CTs to the healthcare system of Alberta, for CTs which began in 2012. The average revenue per noncancer drug CT was $\$ 799$ thousand (with post-trial drugs) and $\$ 467$ thousand (without post-trial drugs). For cancer drug CTs, it was $\$ 630$ thousand per trial. In total, industry-sponsored drug CTs were estimated to contribute $\$ 72.2$ million without posttrial drugs or $\$ 101$ million with post-trial drugs in non-cancer trials included. If US-based drug prices were adjusted to 2.7 times lower, the total contribution was $\$ 50$ million without post-trial drugs or $\$ 78$ million with post-trial drugs in noncancer trials included.

These results are indicators of the cost of services provided to patients, which the Government of Alberta or private payers would have had to pay for in the absence of pharmaceutical clinical trials. This value is also an indication of the contribution to clinical research made by industry in the field. About 3\% of noncancer drug cost and 1\% of cancer drug cost were allocated to the administrative activities of the trials and the remainder went for drugs and patient clinical services. The remainder, more than $95 \%$ of the value of trials went for patient services and drugs in cancer and non-cancer pharmaceutical trials.

Our estimates of the value of drugs within trials can be compared to those obtained from official reports of the drug companies to the national PMPRB (19); these are calculated according to valuation methods set by Revenue Canada, the official national tax agency. PMPRB reported costs include raw materials and labor costs of production, not the retail value of the drugs (which would be at-factory cost plus the cost of sales plus wholesaler and retailer operating costs). Revenue Canada's (and hence PMPRB's) costing method is used to gauge the extent of private investment in research and development. This method is appropriate for comparing a company's direct research and development costs with that company's operating costs - an indicator that the Canadian government uses to assess industry commitment to research. This indicator does not provide an indication of the value of pharmaceuticals provided by industry to healthcare consumers and providers through their funding of clinical trials. For our purposes, the market value of the drugs are better approximations of the value of these drugs that are provided to the consumers.

A second issue concerns the outcomes of the trials. We included all trials, including those whose outcomes did not show superiority of the experimental arms. Our analysis is focused on the value of resources used in the trials, not on outcomes. In this regard, our estimate is not different from any measure of costs or resources used in standard - of - care treatments. Treatments can be unsuccessful in both cases, experimental or 
not. The inclusion of services with all outcomes, good and bad, calls for the recognition that we are measuring the market value (economic activity) of resources used, not the outcomes.

In order to obtain an idea of the relative order of magnitude of these estimates, we can compare them with the funding of clinical research by its funders. Clinical research, as defined by Canadian Institutes of Health Research, is "research with the goal of improving the diagnosis, and treatment (including rehabilitation and palliation), of disease and injury; improving the health and quality of life of individuals as they pass through normal life stages. Clinical research usually encompasses research on, or for the treatment of, patients” (20). Our estimates indicate that, of the total clinical research conducted in Alberta (\$94.6 million in Table 4), industry's contribution to the value of drugs and clinical services in pharmaceutical trials amounted to $\$ 72.2$ million, which is $76 \%$ of all funding for clinical research.

There are several limitations of our analysis. First, we could not get data to estimate the contributions made in post-trial drug expenditures for cancer drug trials. Some components of openlabel trials are quite costly, so the total contribution of industry-sponsored drug CTs could be substantially higher. Second, we obtained the data on the provincial volume of trials from the website, ClinicalTrials.gov. There is no single data source in Canada where you can obtain information on conducting clinical trials and we could have missed some trials which were started in 2012 but did not register this website. Third, we used American valuations of drugs where we could not find Canadian values. The sensitivity analysis results show that adjusting for price differences between the two countries could lead to a substantial reduction in the total contribution of industrysponsored drug CTs. However, it should be noted that the VA FSS is a quantity discount list and its prices could be well below the manufacturers' list prices. In addition, the PMPRB-reported price difference is for all drugs in general while our study included experimental drugs that were not listed in Canada. Therefore, their prices at launch in Canada would be expected to be close with the discounted prices in the United States.

\section{CONCLUSIONS}

We provide new knowledge of the economic value of industry - sponsored pharmaceutical clinical trials. Our findings are in line with a study performed at an academic center in the UK concluding that savings in this field, coming mostly from commercial trials (6).

Table 4: Clinical research expenditures in Alberta by major funders (in \$ thousand), 2013

\begin{tabular}{|c|c|c|c|}
\hline Funding group & $\begin{array}{c}\text { Total operating } \\
\text { grants }\end{array}$ & Clinical research & Source \\
\hline Industry (pharmaceutical companies) & N/A & $\$ 72,167$ & 1 \\
\hline Canadian Institute for Health Research (CIHR) & $\$ 63,608$ & $\$ 7,388$ & 2 \\
\hline Alberta Innovates Health Solutions (AIHS) & $\$ 87,921$ & $\$ 14,220$ & 3 \\
\hline Heart and Stroke Foundation Canada & $\$ 2,299$ & $\$ 499$ & 4 \\
\hline Canadian Cancer Society & $\$ 1,298$ & $\$ 319$ & 5 \\
\hline Prostate Cancer Canada & $\$ 0$ & $\$ 60$ & 6 \\
\hline Total identified sources & $\$ 155,126$ & $\$ 94,653$ & \\
\hline
\end{tabular}

\section{Sources:}

N/A Not available

1. Table 3, excluding open label components

2. Unpublished data obtained from CIHR.

3. Unpublished data obtained from AIHS (Deanne Langlois - Klassen)

4. Heart and Stroke Foundation Research Report 2012-2013.

5. http://webapps.cihr-irsc.gc.ca/funding/Search?p_language=E\&p_version=CCS

6. http://webapps.cihr-irsc.gc.ca/cris/Search?p_language=E\&p_version=PCC 


\section{FUNDING}

This study was funded by Alberta Innovates Health Solutions.

\section{COMPLIANCE WITH ETHICAL STANDARDS}

All authors declare that they have no conflict of interest. Dat T. Tran and Ilke Akpinar received financial support from Alberta Innovates Health Solutions.

\section{AUTHOR CONTRIBUTIONS}

Richard Fedorak, Philip Jacobs, and Egon Jonsson conceptualized the study. Ilke Akpinar searched the ClinicalTrials.gov for the trials details. Dat T. Tran carried out the costing analyses. Philip Jacobs and Dat T. Tran drafted the manuscript. All authors contributed to the writing of the manuscript and critically reviewed the manuscript for intellectual content.

\section{ACKNOWLEDGMENTS}

We would like to acknowledge the contribution of the following persons who provided constructive comments and helped us with obtaining data: Arto Ohinmaa, University of Alberta and Institute of Health Economics; Rae Emogene and Ron Welch, NACTRC; Diane Kinnear and Sharon Appelman, Alberta Health Services; Kim Kordov, University of Alberta; Deanne Langlois - Klassen, Alberta Innovates Health Solutions; Bob McQueen, Medicine Shop; Nianda Penner, CADTH; Chad Mitchell and Ian Robertson, Alberta Health; Tanya Potashnik, Patented Medicine Price Review Board; Ian Robertson, Alberta Health; and Anne Babineau, Innovative Medicines Canada. We would like to thank Alberta Innovates Health Solutions for funding of this project.

\section{REFERENCES}

1. Bredin C, Eliasziw M, Syme R. Drug cost avoidance resulting from cancer clinical trials. Contemp Clin Trials. 2010;31(6):524-9.

2. LaFleur J, Tyler LS, Sharma RR. Economic benefits of investigational drug services at an academic institution. Am J Health Syst Pharm. 2004;61(1):2732.

3. McDonagh MS, Miller SA, Naden E. Costs and savings of investigational drug services. Am J Health Syst Pharm. 2000;57(1):40-3.
4. Shen LJ, Chou H, Huang CF, Chou GM, Chan WK, Wu FL. Economic benefits of sponsored clinical trials on pharmaceutical expenditures at a medical center in Taiwan. Contemp Clin Trials. 2011;32(4):485-91.

5. Wright JR, Roche K, Smuck B, Cormier J, Cecchetto S, Akow M, et al. Estimating per patient funding for cancer clinical trials: an Ontario based survey. Contemp Clin Trials. 2005;26(4):421-9.

6. Liniker E, Harrison M, Weaver JM, Agrawal N, Chhabra A, Kingshott V, et al. Treatment costs associated with interventional cancer clinical trials conducted at a single UK institution over 2 years (2009-2010). Br J Cancer. 2013;109(8):2051-7.

7. Canadian Institute for Health Information. National Health Expenditure Trends, 1975 to 2014. 2014.

8. National Institutes of Health. ClinicalTrials.gov [cited 2016 June 9]. Available from: https://clinicaltrials.gov/ct2/home.

9. Akpinar I, Jacobs P, Tran TD. Forecasting Pharmaceutical Prices for Economic Evaluations When There Is No Market: A Review. PharmacoEconomics - Open. 2016;1(1):65-8.

10. Alberta Health. Interactive Drug Benefit List 2016 [cited 2016 September 10]. Available from: https://www.ab.bluecross.ca/dbl/publications.html.

11. Office of Acquisition and Logistics- U.S. Department of Veterans Affairs. Pharmaceutical Prices 2016 [cited 2016 June 6]. Available from: http://www.va.gov/oal/business/fss/pharmPrices.asp.

12. Bank of Canada. Exchange Rates [cited 2016 July 8]. Available from: http://www.bankofcanada.ca/rates/exchange/.

13. Medscape. Medscape [cited 2016 June 9]. Available from: http://www.medscape.com/.

14. Lowin J, Bergman A, Chaudhuri KR, Findley LJ, Roeder C, Schifflers M, et al. A cost-effectiveness analysis of levodopa/carbidopa intestinal gel compared to standard care in late stage Parkinson's disease in the UK. J Med Econ. 2011;14(5):584-93.

15. Selleckchem. 2016 [cited 2016 June 9]. Available from: http://www.selleckchem.com.

16. Medchem Express. 2016 [cited 2016 June 9]. Available from: http://www.medchemexpress.com/.

17. Smilski K. (Professional Services and Health Benefits Division- Alberta Health). Personal communication on MODERIBA price on August 25, 2017. 2017.

18. Patented Medicine Price Review Board Annual Report, 2015. Ottawa; 2016. Report No.: 1495-0561.

19. Patented Medicine Price Review Board Annual Report, 2013. Ottawa; 2013.

20. Canadian Institutes of Health Research. The Four Themes of CIHR Funded Health Research 2014 [cited 2017 January 12]. Available from: http://www.cihr-irsc.gc.ca/e/48801.html. 